\title{
Dyspnoea and hypoxaemia after lung surgery: the role of interatrial right-to-left shunt
}

\author{
C. Marini*,\#, M. Miniati" ${ }^{\star}$, N. Ambrosino ${ }^{+}$, B. Formichi*, L. Tonelli*, G. Di Ricco*, \\ C. Michelassi*, S. Giusti $i^{\S}$ and I. Spadoni ${ }^{\S}$
}

ABSTRACT: After lung surgery, some patients complain of unexplained increased dyspnoea associated with hypoxaemia. This clinical presentation may be due to an interatrial right-to-left shunt despite normal right heart pressure. Some of these patients show postural dependency of hypoxaemia, whereas others do not.

In this article, the pathogenesis and mechanisms involved in this post-surgical complication are discussed, and the techniques used for confirmation and localisation of shunt are reported.

An invasive technique, such as right heart catheterisation with angiography, was often used in the past as the diagnostic procedure for the visualisation of interatrial shunt. As to noninvasive techniques, a perfusion lung scan may be used as the first approach as it may detect the effect of the right-to-left shunt by visualising an extrapulmonary distribution of the radioactive tracer. The $100 \%$ oxygen breathing test could also be used to quantify the amount of right-to-left shunt. Particular emphasis is given to newer imaging modalities, such as transoesophageal echocardiography, which is minimally invasive but highly sensitive in clearly visualising the atrial septum anatomy.

Finally, the approch to closure of the foramen ovale or atrial septal defect is discussed. Open thoracotomy was the traditional approach in the past. Percutaneous closure has now become the most used and effective technique for the repair of the interatrial anatomical malformation.

\section{KEYWORDS: Heart septal defect, lung surgery, postural hypoxaemia}

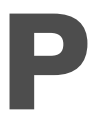
atients who have undergone pulmonary resection commonly complain of dyspnoea, which is frequently attributed to the loss of alveolar volume and restriction of the pulmonary vascular bed $[1,2]$.

However, some of these patients show a sudden and unexplained onset of dyspnoea due to an interatrial right-to-left shunt through a previously asymptomatic patent foramen ovale (PFO) or atrial septal defect (ASD) with normal right heart pressure [3-6].

One of the peculiar aspects of this complication is its possible association with so-called platypnoea (flat breathing), defined as dyspnoea induced by upright posture and relieved by recumbency [7], and orthodeoxia, defined as arterial oxygen desaturation accentuated by upright posture and improved by recumbency [8].

Two previous reviews of the literature $[5,6]$ reported several cases of patients observed during the period 1956-1992 who showed a right-to-left interatrial shunt after lung surgery that, in most instances, was associated with platypnoea-orthodeoxia syndrome. This syndrome occurred a month to several months after pulmonary resection and was not associated with pulmonary hypertension [3-5, 9-29].

By contrast, there have been only a few reports describing dyspnoea and hypoxaemia due to an interatrial right-to-left shunt occurring shortly after lung surgery [23, 30-38]. In most instances, these respiratory manifestations were not posture-dependent.

The peculiarity of this post-surgical complication prompted the present review of the data reported in the literature to gain insight into its pathogenesis.

\section{METHODS}

The PubMed database was searched for all case reports dealing with the occurrence of dyspnoea and hypoxaemia after lung surgery due to an interatrial right-to-left shunt. Bibliographies from

\section{AFFILIATIONS}

*Pulmonary Unit, Clinical Physiology Institute, National Research Council, \#Respiratory Pathophysiology, Cardiothoracic Department, University of Pisa, and +Pulmonary Unit, Cardiothoracic Department, University Hospital, Pisa, and

"Dept of Critical Care, Respiratory Medicine Section, University of Florence, Florence, and

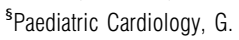
Pasquinucci Hospital, Clinical Physiology Institute, National Research Council, Massa, Italy.

\section{CORRESPONDENCE}

C. Marini

Reparto Polmonare

Istituto di Fisiologia Clinica

CNR

Via G. Moruzzi 1

56124 Pisa

Italy

Fax: 39503152166

E-mail: marini@ifc.cnr.it

Received:

January 172005

Accepted after revision:

February 162006

European Respiratory Journal

Print ISSN 0903-1936

Online ISSN 1399-3003 
pertinent articles and two previous reviews $[5,6]$ were also scanned for suitable articles on this topic.

The search identified 33 studies concerning 46 patients during the period 1956-2004, all included in the final analysis.

Data on age, sex and the methods used for the diagnosis were evaluated. Separate lists were made of those cases who showed a sudden onset of respiratory symptoms $\geqslant 1$ month following lung surgery (group A) and those in whom the symptoms occurred within 1 month after the surgical procedure (group B). The following factors were taken into account: 1) the number of patients in each study; 2) the type of surgery performed; 3 ) the interval between surgery and the onset of symptoms (symptomless interval); 4) the cause of the shunt; and 5$)$ arterial oxygen tension $\left(\mathrm{Pa}_{2} \mathrm{O}_{2}\right)$ or saturation $\left(\mathrm{Sa}_{1} \mathrm{O}_{2}\right)$ in the sitting and supine positions, in order to assess the posture dependency of dyspnoea and hypoxaemia, platypnoeaorthodeoxia syndrome, based on the changes in arterial blood gas data, whenever reported in the sitting and supine position, or, if lacking, the description of the clinical findings in each report, already assigned as posture dependency in the two previous reviews $[5,6]$. In the former event, the presence of platypnoea-orthodeoxia syndrome was assessed according to its current definition, i.e. $\mathrm{a} \geqslant 10 \%$ increase in baseline $\mathrm{Sa}_{1} \mathrm{O}_{2}$ or $\mathrm{Pa}_{1} \mathrm{O}_{2}$ on moving from the sitting to the supine position [39]. In addition, the right atrial pressure, left atrial pressure and pulmonary arterial pressure, as well as the treatment used to close the shunt, and the follow-up of patients were also reported.

\section{Statistics}

Whenever appropriate, the two-tailed paired or unpaired t-test, Levene's test for equality of variance and Fisher's exact test were used to compare haemodynamic parameters, such as mean right atrial pressure, mean left atrial pressure and mean pulmonary arterial pressure, within each group, as well as their differences between groups. Data are reported as mean \pm SD. A p-value of $<0.05$ was considered significant throughout.

\section{RESULTS}

The mean age of the patients listed in tables 1 and 2 (group A; 34 males and two females) was $59 \pm 9 \mathrm{yrs}$ and of those in tables 3 and 4 (group B; eight males and two females) it was $65 \pm 9$ yrs $(p=0.10)$.

\section{Type of lung surgery}

The surgical procedures involved in group A (table 1) were: right pneumonectomy in 24 patients $(67 \%)$, left pneumonectomy in eight $(22 \%)$ and right lobectomy in three $(8 \%)$. In one patient, who underwent thoracotomy due to lung cancer, the type of operation was not reported. The types of surgical procedure in group B (table 2) were: right pneumonectomy in six patients $(60 \%)$, right lobectomy in three $(30 \%)$ and left pneumonectomy in one $(10 \%)$.

Overall, the right side of the chest was more frequently (36 out of $45(80 \%)$ ) involved than the left (nine out of $45(20 \%))$, and lung cancer was the disease affecting all patients.

\section{Symptomless period}

Table 1 shows the cases in which dyspnoea occurred $\geqslant 1$ month following lung surgery; their symptomless period ranged 1-31 months (mean $6 \pm 7$ months).

Table 3 shows the cases in which dyspnoea occurred within 1 month after lung surgery; their symptomless period ranged 1-7 days (mean $3 \pm 3$ days).

\section{Prevalence of congenital abnormality}

Regarding the prevalence of congenital abnormality of the right atrium causing right-to-left shunt, PFO was more frequent by far than ASD: $78 \%$ (28 out of 36) of patients in group A, and $100 \%$ in group B. Regarding the ASD abnormalities, all listed in table 1 (eight out of $36(22 \%)$ patients), the interatrial communication was of the secundum type in five patients, whereas the type was not specified in two patients. In one patient, an atrial septal aneurysm was found at the level of the fossa ovalis.

\section{Type of investigation for the diagnosis}

Regarding diagnostic work-up in these patients, 16 out of the $36(44 \%)$ patients in group A underwent the $100 \%$ oxygen breathing test. In a few of them, the test was performed in both the recumbent and the upright position. In group B, four out of the $10(40 \%)$ patients underwent the $100 \%$ oxygen breathing test.

A perfusion lung scan, which is usually performed to rule out pulmonary embolism in such patients, was obtained in 17 out of $36(47 \%)$ patients in group A and five out of $10(50 \%)$ patients in group B. Nine out of the $17(56 \%)$ perfusion lung scans performed in patients from group A showed no perfusion abnormality, whereas, in the seven other patients, the lung scan showed an extrapulmonary distribution of the radioactive tracer in the brain, thyroid, kidneys and spleen, suggesting the presence of right-to-left shunt [40]. Interestingly, in one of these seven patients, the pattern of extrapulmonary distribution of radioactive tracer was neglected, and, in another patient, the extrapulmonary uptake of the radiotracer became evident 1 month after the initial evaluation, when deterioration of respiratory symptoms had occurred. Of the five lung scans performed in the 10 patients from group $B$, three did not show any perfusion abnormality, and two showed extrapulmonary uptake of the radioactive tracer.

\section{Tests for the diagnosis of right-to-left intracardiac shunt}

Among the 36 patients in group A, intracardiac shunt through PFO or ASD was demonstrated by inferior and/or superior vena cava angiography in $17(47 \%)$ patients, contrast transthoracic or transoesophageal echocardiography in $15(41 \%)$ and right heart catheterisation in two $(6 \%)$, and, in one $(3 \%)$ patient each, by magnetic resonance imaging and open heart surgery.

Regarding the 10 patients in group B, the final diagnosis of intracardiac right-to-left shunt was made by contrast transthoracic or transoesophageal echocardiography in eight $(80 \%)$ patients and right heart catheterisation in two $(20 \%)$.

Overall, the techniques more frequently used for the diagnosis of intracardiac right-to-left shunting in this series of 46 patients were, in order, angiography (17 patients), contrast 


\begin{tabular}{|c|c|c|c|c|c|}
\hline First author [ref.] & Case No. & Surgery & Symptomless interval months & Shunt cause & Posture-dependent \\
\hline SchnabeL [3] & 1 & $\mathrm{RP}$ & 1 & PFO & + \\
\hline WinTERS [4] & 2 & $\mathrm{RP}$ & 3 & ASD & + \\
\hline BeGIN [9] & 3 & $\mathrm{RP}$ & 2 & ASD & + \\
\hline HoLtZMan [11] & 5 & $\mathrm{RP}$ & 1.5 & ASD & - \\
\hline LABRESH [12] & 6 & LP & 5 & ASD & + \\
\hline Roos [13] & 7 & LP & 2 & PFO & + \\
\hline SPRINGER [14] & 8 & $\mathrm{RL}$ & 4 & PFO & + \\
\hline \multirow[t]{2}{*}{ Seward [15] } & 9 & $\mathrm{RP}$ & 7 & PFO & + \\
\hline & 10 & LP & 5 & PFO & + \\
\hline \multirow[t]{4}{*}{ van Rossum [17] } & 15 & $\mathrm{RP}$ & 3 & PFO & + \\
\hline & 16 & $\mathrm{RP}$ & 2 & PFO & + \\
\hline & 17 & $\mathrm{RP}$ & 4 & PFO & + \\
\hline & 18 & $\mathrm{RP}$ & 27 & PFO & + \\
\hline SmEENK [18] & 19 & LP & 2 & PFO & + \\
\hline DARREMONT [19] & 20 & $\mathrm{RP}$ & 3 & PFO & + \\
\hline Buss $[20]$ & 21 & $\mathrm{RP}$ & 6 & PFO & + \\
\hline \multirow[t]{2}{*}{ TIMMERMANS [21] } & 22 & $\mathrm{RP}$ & 1 & ASA & + \\
\hline & 23 & $\mathrm{RP}$ & 1 & ASD & + \\
\hline \multirow[t]{2}{*}{ МERCHO [22] } & 24 & $\mathrm{RP}$ & 6 & PFO & + \\
\hline & 25 & $\mathrm{RP}$ & 12 & PFO & + \\
\hline VINCENT [27] & 33 & $\mathrm{RP}$ & 6 & PFO & + \\
\hline \multirow[t]{2}{*}{ DANNER [28] } & 34 & $\mathrm{RP}$ & 3 & PFO & + \\
\hline & 35 & $\mathrm{RP}$ & 3 & PFO & + \\
\hline MARINI [29] & 36 & $\mathrm{RP}$ & 5 & PFO & + \\
\hline
\end{tabular}

RP: right pneumonectomy; LP: left pneumonectomy; RL: right lobectomy; THOR: thoracotomy; PFO: patent foramen ovale; ASD: atrial septal defect; ASA: atrial septal aneurysm; +: posture-dependent dyspnoea; -: posture-independent dyspnoea. ${ }^{*}: 10 \mathrm{yrs}$ after diagnosis of right-to-left shunt.

transoesophageal echocardiography (12) and contrast transthoracic echocardiography (11).

\section{Posture-dependent abnormalities in gas exchange}

As shown in table 1, platypnoea-orthodeoxia syndrome was present in 33 out of the $36(92 \%)$ patients in group $\mathrm{A}$, and it occurred $\geqslant 1$ month after lung surgery. In 19 of these subjects, the finding of platypnoea-orthodeoxia was supported by sitting-supine changes in $\mathrm{Pa}_{1} \mathrm{O}_{2}$ or $\mathrm{Sa}_{1} \mathrm{O}_{2}$ (table 2) according to the definition reported above [39]. Of the 10 patients who complained of acute dyspnoea shortly after lung surgery, three manifested platypnoea-orthodeoxia syndrome and sittingsupine changes in $\mathrm{Pa}_{2} \mathrm{O}_{2}$ or $\mathrm{Sa}_{2} \mathrm{O}_{2}$ (table 3 and 4 ).

\section{Haemodynamic measurement}

The information regarding haemodynamic parameters is fragmentary. From the available data shown in table 2 (group A), it appears that mean right atrial pressure was $4.3 \pm 3.4$ $\mathrm{mmHg}$ in 27 out of the $36(75 \%)$ patients, mean left atrial pressure was $6.0 \pm 3.5 \mathrm{mmHg}$ in $22(61 \%)$ and mean pulmonary arterial pressure was $14.3 \pm 3.7 \mathrm{mmHg}$ in $26(72 \%$; table 5). Thus, in the patients in group $\mathrm{A}$, the mean pressure gradient between the left and right atrium was $1.07 \pm 3.3 \mathrm{mmHg}$, and the mean pulmonary arterial pressure was normal (table 5).

In group B (table 5), mean right atrial pressure was $7.6 \pm 3.7$ $\mathrm{mmHg}$ in eight out of $10(80 \%)$ patients, whereas mean left 
TABLE 2 Arterial blood gas levels, haemodynamic data and outcome of patients with sudden-onset respiratory symptoms occurring $\geqslant 1$ month after lung surgery (group $A$ )

\begin{tabular}{|c|c|c|c|c|c|c|c|c|c|}
\hline \multirow[t]{2}{*}{ First author [ref.] } & \multicolumn{2}{|c|}{$\mathrm{Pa}, \mathrm{O}_{2} \mathrm{mmHg}$} & \multicolumn{2}{|c|}{$\mathrm{Sa}, \mathrm{O}_{2} \%$} & \multirow[t]{2}{*}{$\bar{P}$ ra $\mathrm{mmHg}$} & \multirow[t]{2}{*}{$\bar{P}_{\text {la }} \mathbf{m m H g}$} & \multirow[t]{2}{*}{$\bar{P}_{\text {pa }} \mathrm{mmHg}$} & \multirow{2}{*}{$\begin{array}{l}\text { Shunt closure } \\
\text { method }\end{array}$} & \multirow[t]{2}{*}{ Follow-up } \\
\hline & Sitting & Supine & Sitting & Supine & & & & & \\
\hline WinTERS [4] & 48 & 78 & NR & NR & NR & NR & NR & Open-chest surgery & $\mathrm{A} ; 1 \mathrm{yr}$ \\
\hline WIHLM [5] & 42 & NR & NR & NR & NR & NR & NR & No closure & D (ARF); 1 month \\
\hline Begin [9] & 34 & 55 & NR & NR & 15 & 12 & NR & Open-chest surgery & NR \\
\hline Holtzman [11] & NR & 34 & NR & NR & 3 & 6 & 15 & Open-chest surgery & D (septic shock); 2 days \\
\hline LABresh [12] & 36 & NR & NR & NR & 0 & NR & 8 & Open-chest surgery & $\mathrm{A} ; 1 \mathrm{yr}$ \\
\hline Roos [13] & 40 & 47 & NR & NR & 0 & NR & 9 & Open-chest surgery & A; 8 months \\
\hline SPRINGER [14] & $44^{\#}$ & $81^{\#}$ & NR & NR & 4 & 10 & 13 & Open-chest surgery & NR \\
\hline \multirow[t]{2}{*}{ SEWARD [15] } & 71 & NR & NR & NR & 6 & 9 & 16 & Open-chest surgery & $\mathrm{A} ; 8 \mathrm{yrs}$ \\
\hline & 43 & 56 & NR & NR & 1 & 8 & 16 & Open-chest surgery & D (massive $\mathrm{Cl}$ ); 7 days \\
\hline \multirow{3}{*}{ van Rossum [17] } & NR & NR & NR & NR & 2 & 2 & 14 & Open-chest surgery & A; 2-10 months" \\
\hline & NR & NR & NR & NR & 3 & 2 & 8 & Open-chest surgery & A; $2-10$ months \\
\hline & NR & NR & NR & NR & 3 & NR & 11 & Open-chest surgery & A; $2-10$ months \\
\hline SmeEnK $[18]$ & & & 68.5 & NR & 4 & 2 & 10 & Open-chest surgery & A; discharge \\
\hline DARREMONT [19] & & & 83 & 92 & 10 & 7 & 17 & Open-chest surgery & $\mathrm{A} ; 1 \mathrm{yr}$ \\
\hline Buss $[20]$ & & & 75 & 87 & 5 & NR & 13 & Open-chest surgery & A; 5 yrs \\
\hline \multirow{2}{*}{ TIMMERMANS [21] } & $33^{+}$ & $57^{+}$ & NR & NR & 4.5 & 2.5 & 15 & Open-chest surgery & A; discharge \\
\hline & NR & NR & NR & $N R$ & 4.5 & 3.5 & 14 & Open-chest surgery & A; discharge \\
\hline \multirow[t]{2}{*}{ MeRCHO [22] } & NR & NR & $83^{\S}$ & $92^{\S}$ & NR & NR & NR & Open-chest surgery & A; discharge \\
\hline & NR & NR & $47^{\S}$ & $56^{\S}$ & NR & NR & NR & Open-chest surgery & A; discharge \\
\hline LANDZBERG [23] & NR & NR & $70 / 80$ & 98 & 7 & 7 & 19 & Transcatheter & A; 50 months \\
\hline VINCENT [27] & 51 & 61 & NR & NR & NR & NR & NR & Transcatheter & A; 1.5 months \\
\hline \multirow[t]{2}{*}{ DANNER [28] } & NR & NR & 80 & 93 & $N R$ & NR & NR & Open-chest surgery & A; 7 months \\
\hline & NR & NR & 83 & 92 & NR & NR & NR & Open-chest surgery & A; discharge \\
\hline MARINI [29] & 43 & 74 & NR & NR & 3 & 3 & 11 & Transcatheter & A; 2 yrs \\
\hline
\end{tabular}

$\mathrm{Pa}_{\mathrm{a}} \mathrm{O}_{2}$ : arterial oxygen tension; $\mathrm{Sa}_{1} \mathrm{O}_{2}$ : arterial oxygen saturation; $\bar{P}_{\mathrm{ra}}$ : mean right atrial pressure; $\bar{P}_{\mathrm{la}}$ : mean left atrial pressure; $\bar{P}_{\text {pa: }}$ mean pulmonary arterial pressure; NR: not reported; A: alive; D: dead; Cl: cerebral infarction; ARF: acute respiratory failure. ${ }^{*}$ : breathing 40\% oxygen; " ${ }^{\natural}$ follow-up of these patients ranged $2-10$ months; ${ }^{+}$ breathing $3.5 \mathrm{~L} \cdot \mathrm{min}^{-1}$ oxygen; ${ }^{\text {s: }}$ breathing $100 \%$ oxygen. $1 \mathrm{mmHg}=0.133 \mathrm{kPa}$.

atrial pressure was $7.1 \pm 3.6 \mathrm{mmHg}$ in seven $(70 \%)$ patients and mean pulmonary arterial pressure $21.8 \pm 10.7 \mathrm{mmHg}$ in six $(60 \%)$. Interestingly, the mean right atrial pressure in patients in group $B$ was significantly higher than that of patients in group A ( $7.6 \pm 3.7$ versus $4.3 \pm 3.4 \mathrm{mmHg}$, respectively; $\mathrm{p}<0.05$; table 5). The mean pulmonary arterial pressure in patients in group B $(21.8 \pm 10.7 \mathrm{mmHg})$ was also higher than that of patients in group A $(14.3 \pm 3.7 \mathrm{mmHg})$, although the difference did not attain significance $(\mathrm{p}=0.15)$.

\section{Closure of interatrial communication}

Overall, the methods used to close a PFO or ASD in these 46 patients were: open-chest surgical closure in $32(70 \%)$ patients, transcatheter permanent implantation of a device placed across the interatrial communication [23] in eight (17\%) and a pulmonary arterial catheter with a balloon inflated in the left atrium for temporary closure in one $(2 \%$; table 2$)$. In the five $(11 \%)$ other patients, four in group A (table 2) and one in group B (table 4), the interatrial communication was not closed. Indeed, 
TABLE 3 Clinical characteristics of patients with sudden-onset respiratory symptoms occurring within 1 month of lung surgery (group B)

\begin{tabular}{|c|c|c|c|c|c|}
\hline First author [ref.] & Case No. & Surgery & Symptomless interval days & Shunt cause & Posture-dependent \\
\hline DLABAL [30] & 1 & $\mathrm{RP}$ & 7 & PFO & - \\
\hline HAZARD [32] & 3 & $\mathrm{RP}$ & 2 & PFO & - \\
\hline BERRY [33] & 4 & LP & 1 & PFO & + \\
\hline SAADA [34] & 5 & $\mathrm{RP}$ & 1 & PFO & - \\
\hline Alfaifi [36] & 8 & RL & 7 & PFO & - \\
\hline GodART [37] & 9 & $\mathrm{RP}$ & 2 & PFO & NR \\
\hline MALL [38] & 10 & $\mathrm{RP}$ & 2 & PFO & + \\
\hline
\end{tabular}

RP: right pneumonectomy; RL: right lobectomy; LP: left pneumonectomy; PFO: patent foramen ovale; NR: not reported; +: posture-dependent dyspnoea; -: postureindependent dyspnoea.

TABLE 4 Arterial blood gas levels, haemodynamic data and outcome of patients with sudden-onset respiratory symptoms occurring within 1 month of lung surgery (group B)

\begin{tabular}{|c|c|c|c|c|c|c|c|c|c|}
\hline \multirow[t]{2}{*}{ First author [ref.] } & \multicolumn{2}{|c|}{$\mathrm{Pa}, \mathrm{O}_{2} \mathrm{mmHg}$} & \multicolumn{2}{|c|}{$\mathrm{Sa}, \mathrm{O}_{2} \%$} & \multirow[t]{2}{*}{$\bar{P}_{\text {ra }} \mathrm{mmHg}$} & \multirow[t]{2}{*}{ Ṕla mmHg } & \multirow[t]{2}{*}{$\bar{P}$ pa $\mathrm{mmHg}$} & \multirow[t]{2}{*}{ Shunt closure method } & \multirow[t]{2}{*}{ Follow-up } \\
\hline & Sitting & Supine & Sitting & Supine & & & & & \\
\hline DLABAL [30] & $156^{\#}$ & $148^{\#}$ & NR & NR & 10 & 6 & 20 & Open-chest surgery & A; 21 months \\
\hline VACEK $[\mathbf{3 1}]$ & NR & 50 & NR & NR & 4 & 2 & 10 & Open-chest surgery & A; discharge \\
\hline HAZARD [32] & $N R^{*}$ & $64^{\circ}$ & NR & NR & 14 & 12 & 41 & Balloon inflated in left atrium & $\begin{array}{c}\text { D (pneumothorax); } \\
2 \text { days }\end{array}$ \\
\hline BERRY [33] & NR & NR & 55 & 71 & 5 & NR & 20 & Open-chest surgery & D (sepsis); 1 month \\
\hline SAADA [34] & NR & 46 & NR & NR & 7 & 10 & 25 & No closure $^{+}$ & $\begin{array}{c}\text { D (cancer progression); } \\
2 \text { months }\end{array}$ \\
\hline LANDZBERG [23] & NR & NR & $80 / 90$ & 95 & 6 & 6 & 15 & Transcatheter & $\begin{array}{c}\text { D (cancer progression); } \\
3 \text { months }\end{array}$ \\
\hline GodART [35] & NR & NR & NR & NR & 4 & 4 & NR & Transcatheter & A; 6 months \\
\hline ALFAIFI [36] & 40 & NR & $N R$ & NR & NR & NR & $N R$ & Open-chest surgery & A; discharge \\
\hline GoDART [37] & NR & NR & NR & NR & 11 & 10 & NR & Transcatheter & D (septic shock); 1 day \\
\hline MALL [38] & 50 & 72 & $N R$ & NR & NR & $N R$ & NR & Open-chest surgery & $\mathrm{A}$; discharge \\
\hline
\end{tabular}

$\mathrm{Pa}_{1} \mathrm{O}_{2}$ : arterial oxygen tension; $\mathrm{Sa}_{1} \mathrm{O}_{2}$ : arterial oxygen saturation; $\bar{P}_{\text {ra: }}$ mean right atrial pressure; $\bar{P}_{\text {la: }}$ mean left atrial pressure; $\bar{P}_{\text {pa: }}$ mean pulmonary arterial pressure; NR: not reported; A: alive; D: dead. ${ }^{*}$ : breathing $100 \%$ oxygen; $"$ : breathing $40 \%$ oxygen; ${ }^{+}$: hypoxaemia spontaneously relieved and surgical closure not considered free of risk. $1 \mathrm{mmHg}=0.133 \mathrm{kPa}$.

patient No. 4 showed marked clinical improvement once diuretics and digoxin were withdrawn [10], patient No. 11 was followed up for 8 months after diagnosis and the surgical intervention was still under consideration at the time of the report [15], patient No. 14 was deemed too ill to undergo surgery [5] and patient No. 30 did not undergo surgery owing to a very poor prognosis due to the progression of lung cancer [25]. Patient No. 5 in group B did not undergo surgical intervention, in part due to the spontaneous partial improvement of clinical symptoms, but mainly due to a poor prognosis [34].

\section{Follow-up studies}

In table 2, the follow-up of patients of group A is reported. Overall, four out of the $36(11 \%)$ patients died, two of them a few days after surgery.

Sixteen $(50 \%)$ patients were followed-up for a mean period of $26 \pm 25$ months (range 1.5-96 months). In eight (25\%) patients, the follow-up ended at the time of their discharge from the hospital, in four (12.5\%) it ranged 2-10 months, and, in the remaining four $(12.5 \%)$, the follow-up period was not reported (table 2). 


\begin{tabular}{|c|c|c|c|}
\hline \multirow[t]{2}{*}{ TABLE 5} & \multicolumn{3}{|c|}{$\begin{array}{l}\text { Comparison of haemodynamic variables in the } \\
\text { two groups of patients }\end{array}$} \\
\hline & Group A & Group B & $p$-value \\
\hline Subjects n & 36 & 10 & \\
\hline \multicolumn{4}{|l|}{$\bar{P}_{\mathrm{ra}}$} \\
\hline $\mathrm{mmHg}$ & $4.3 \pm 3.4$ & $7.6 \pm 3.7$ & 0.02 \\
\hline n (\%) & 27 (75) & $8(80)$ & \\
\hline \multicolumn{4}{|l|}{$\bar{P}_{\mathbf{l a}}$} \\
\hline $\mathrm{mmHg}$ & $6.0 \pm 3.5$ & $7.1 \pm 3.6$ & 0.42 \\
\hline n (\%) & $22(61)$ & 7 (70) & \\
\hline \multicolumn{4}{|l|}{$\overline{\boldsymbol{P}} \mathrm{pa}$} \\
\hline $\mathrm{mmHg}$ & $14.3 \pm 3.7$ & $21.8 \pm 10.7$ & 0.15 \\
\hline n (\%) & $26(72)$ & $6(60)$ & \\
\hline \multicolumn{4}{|l|}{$\bar{P}_{\mathbf{l a}}-\bar{P}_{\mathbf{r a}}$} \\
\hline $\mathrm{mmHg}$ & $1.07 \pm 3.3$ & $-0.86 \pm 2.2$ & 0.16 \\
\hline n (\%) & $23(64)$ & 7 (70) & \\
\hline
\end{tabular}

Data are presented as mean \pm SD, unless otherwise stated. $\bar{P}$ ra: mean right atrial pressure; $\bar{P}$ a: mean left atrial pressure; $\bar{P}$ pa: mean pulmonary arterial pressure. $1 \mathrm{mmHg}=0.133 \mathrm{kPa}$

Regarding patients in group B (table 4), death occurred in five out of $10(50 \%)$ patients, with two dying 1 day and 3 months after transcatheter $\mathrm{PFO}$ closure, respectively. Of the five patients who survived, three were followed-up until hospital discharge, one was followed-up for 6 months, one for 21 months, after PFO closure (table 4).

\section{DISCUSSION}

From the survey of the literature, 46 cases of patients who had undergone pulmonary resection and developed, over a variable period of time after surgery, unexplained dyspnoea with hypoxaemia that, in several cases, was posture-dependent were reviewed. This surgical complication was due to an interatrial right-to-left shunt through a PFO or ASD with normal right heart pressures.

\section{Mechanisms involved in right-to-left shunt}

The type and site of pulmonary resection do not appear to affect the time of onset of right-to-left shunt. Indeed, it occurred after right pneumonectomy, as well as after resection of a few pulmonary segments.

Similarly, the nature of the congenital abnormality, be it PFO or ASD, does not in itself explain the time of occurrence of right-to-left shunting. Indeed, both of these congenital abnormalities were usually asymptomatic before pulmonary resection [18].

By grouping patients as a function of the symptomless interval, it was found that platypnoea-orthodeoxia syndrome was present in $92 \%$ of patients of group A (table 1), in whom the symptomless interval averaged $6 \pm 7$ months. On the contrary, in the 10 patients of group B (table 3), in whom the symptomless interval was $3 \pm 3$ days, platypnoea-orthodeoxia syndrome was present in three out of the nine (33\%) patients for whom these data were available (table 3). Thus, the syndrome was significantly more frequent in patients in whom respiratory symptoms developed several months after lung surgery $(\mathrm{p}<0.001$; Fisher's exact test).

The late occurrence of symptoms in patients with platypnoeaorthodeoxia (group A; table 1) may be the result of relatively slow anatomical remodelling after lung resection. Indeed, the obliteration of the post-pneumonectomy space usually takes 3 weeks to 7 months [41]. The shift of the mediastinum towards the operated side may be extensive when the obliteration of the pleural space is complete. In this case, the interatrial stretching can be conspicuous [42] and right-to-left shunting through a PFO or an ASD may develop (mainly in the upright position) despite normal right atrial pressure [8]. The interatrial stretching seems to be the mechanism of the streaming of blood from the inferior vena cava to the left atrium in the absence of a pressure gradient, particularly in the presence of mediastinal distortion, when the right atrium is shifted away, while the inferior vena cava remains fixed in position [16]. This mechanism appears operative in patients of group $\mathrm{A}$, despite the fact that the mean left atrial pressure was higher than the mean right atrial pressure (table 5). However, it has been suggested recently that the mobility of the fossa ovalis membrane might favour and enhance the flow towards the foramen ovale [43]. This additional mechanism seems to be operative during mid-systole, when a pronounced motion of the atrial septum toward the left atrium occurs [44]. Furthermore, as shown in table 5, the mean pulmonary arterial pressure was normal $(14.3 \pm 3.7 \mathrm{mmHg})$. Therefore, the occurrence of right-to-left shunting through a pressure gradient mechanism appears unlikely in these patients.

In group $B$, the mean right atrial pressure was higher than the mean left atrial pressure in four of the seven patients in whom these data were available (table 4). By comparing the mean right atrial pressure between the two groups (table 5), it appears that the mean right atrial pressure in most patients of group B was significantly higher than that found in patients of group A $(7.6 \pm 3.7$ versus $4.3 \pm 3.4 \mathrm{mmHg} ; \mathrm{p}<0.05)$. Moreover, the mean pulmonary arterial pressure was higher in patients of group B than in those of group A.

Thus, in this case, the shunt could occur as a consequence of a sudden increase in pulmonary vascular resistance and a decrease in right ventricular compliance [45] following surgical reduction of the pulmonary vascular bed [18]. In addition, the intra- and perioperative fluid overload, which is known to impair right heart function in pulmonary resection [46, 47], could also act through the same mechanism in these patients.

Interestingly, three of the 10 patients in group B showed platypnoea-orthodeoxia syndrome, although it has been demonstrated that this complication more frequently occurs as a late post-pneumonectomy complication.

In case No. 4 (group B), who underwent left pneumonectomy, the mean right atrial and pulmonary arterial pressures were higher than the corresponding mean pressures of patients in group B (tables 4 and 5). Therefore, the sudden increase in flow in the right lung may have caused an interatrial right-toleft shunt in this patient, with a further increase in the fraction of shunted blood in the sitting position. In case No. 6 (group B), the mean pressure in both atria was identical and the rightto-left shunt could occur on moving to the sitting position due 
to a gravity-dependent increase in blood flow [48]. Thus, the pressure gradient mechanism seems to be the trigger of this clinical feature, even in two of the three cases who showed posture dependency of shunt shortly after surgery. Conversely, six out of the seven $(86 \%)$ patients with available data in group $\mathrm{B}$ exhibited a baseline mean right atrial pressure higher than, or at least equal to, that of the left atrium.

\section{Diagnostic and therapeutic management}

Once the suspicion of right-to-left shunt is raised, the $100 \%$ oxygen breathing test may be useful, particularly when it is performed in the sitting and supine position. Indeed, it appears that 20 out of the $46(43 \%)$ patients reported here had $\mathrm{Pa}_{1} \mathrm{O}_{2}$ while breathing $100 \%$ oxygen that were compatible with the presence of right-to-left shunting.

A perfusion lung scan may also show findings suggestive of right-to-left shunt, such as extrapulmonary distribution of radioactive tracer in the brain, thyroid, kidneys and spleen, particularly when the radiotracer injection is performed with the patient in the sitting position [25, 29].

In order to confirm the diagnosis of interatrial right-to-left shunt, right heart angiography was the technique more frequently used until 1988 [28]. Nowadays, it has been progressively replaced by contrast transthoracic or transoesophageal echocardiography, performed in $29(63 \%)$ patients in the present series. Indeed, the latter technique is far less expensive and less invasive than angiography, although equally reliable.

Regarding the procedure used to close the interatrial shunt, open-chest surgery was the technique of choice in 32 out of the $46(70 \%)$ patients of the present series. Since the mid-1990s, open heart surgery has been progressively replaced by transcatheter device implantation across the interatrial communication. This therapeutic option has been successfully applied in 78 patients from the French PFO registry who had platypnoea-orthodeoxia syndrome of various aetiology [49].

\section{Follow-up of patients}

Follow-up data show that nine patients died, four (11\%) from group A and five (50\%) from group B. Of these patients, only four died within a few days after interatrial communication closure, three of them after surgery and one after transcatheter device implantation.

The high rate of death of patients in group B is probably accounted for by their poor clinical conditions, as suggested, on the basis of the available data, by their very low $\mathrm{Pa}_{\mathrm{a}} \mathrm{O}_{2}$ and/ or $\mathrm{Sa}_{\mathrm{a}} \mathrm{O}_{2}$. The occurrence of death in this group of patients appears independent of the method used to close the interatrial communication, be it surgery or transcatheter device implantation.

\section{CONCLUSIONS}

The mechanism of occurrence of posture-dependent hypoxaemia seems to characterise a population of patients in whom right-to-left shunt is a late complication of post-surgical intrathoracic anatomical remodelling.

Conversely, in those patients in whom hypoxaemia occurs shortly after thoracic surgery, right-to-left shunt seems to be induced by a decrease in right ventricular compliance following a reduction of the pulmonary vascular bed and/or by the intra- and perioperative fluid overload, which, in turn, may generate a right-to-left atrial pressure gradient.

Regarding the diagnosis of this post-surgery complication, contrast echocardiography (either transthoracic or transoesophageal) appears a safe and reliable technique.

Finally, regarding treatment, the use of transcatheter device implantation seems to be an effective and minimally invasive approach to this syndrome.

\section{REFERENCES}

1 McIroy MB, Bates DV. Respiratory function after pneumonectomy. Thorax 1956; 11: 303-311.

2 Burrows B, Harrison RW, Adams WE, Humphreys EM, Long ET, Reiman AF. The post-pneumonectomy state. Am J Med 1960; 28: 281-297.

3 Schnabel TG, Ratto O, Kirby CK, Johnson J, Comroe JH Jr. Postural cyanosis and angina pectoris following pneumonectomy: relief by closure of an interatrial septal defect. $J$ Thorac Cardiovasc Surg 1956; 32: 246-250.

4 Winters WL, Cortes F, McDonough M, et al. Venoarterial shunting from inferior vena cava to left atrium in atrial septal defects with normal right heart pressures. Report of two cases. Am J Cardiol 1967; 19: 293-300.

5 Wihlm JM, Roeslin N, Dumont P, Morand G, Witz JP. Insuffisance respiratoire après pneumonectomie par shunt droite-gauche intracardiaque. [Respiratory insufficiency after pneumonectomy due to an intracardiac right-left shunt]. Ann Chir 1986; 40: 611-616.

6 Smeenk FWJ, Postmus PE. Interatrial right-to-left shunting developing after pulmonary resection in the absence of elevated right-sided heart pressures. Review of the literature. Chest 1993; 103: 528-531.

7 Altman M, Robin ED. Platypnea (diffuse zone I phenomenon)? N Engl J Med 1969; 281: 1347-1348.

8 Robin ED, Laman D, Horn BR, Theodore J. Platypnea related to orthodeoxia caused by true vascular lung shunt. N Engl J Med 1976; 294: 941-943.

9 Begin R. Platypnea after pneumonectomy. N Engl J Med 1975; 293: 342-343.

10 Wranne B, Tolagen K. Platypnoea after pneumonectomy caused by a combination of intracardiac right to left shunt and hypovolaemia. Relief of symptoms on restitution of blood volume. Scand J Thorac Cardiovasc Surg 1978; 12: 129-131.

11 Holtzman H, Lippmann M, Nakhjavan F, Kimbel P. Postpneumonectomy interatrial right to left shunt. Thorax 1980; 35: 307-309.

12 LaBresh KA, Pietro DA, Coates EO, Khuri SF, Folland ED, Parisi AF. Platypnea syndrome after left pneumonectomy. Chest 1981; 79: 605-607.

13 Roos CM, Romijn KH, Braat MCP, van Leeuwen AM. Posture-dependent dyspnea and cyanosis after pneumonectomy. Eur J Respir Dis 1981; 62: 377-382.

14 Springer RM, Gheorghiade M, Chakko CS, et al. Platypnea and interatrial right-to-left shunting after lobectomy. Am J Cardiol 1983; 51: 1802-1803.

15 Seward JB, Hayes DL, Smith HC, et al. Platypneaorthodeoxia: clinical profile, diagnostic workup, 
management, and report of seven cases. Mayo Clin Proc 1984; 59: 221-231.

16 Franco DP, Kinasewitz GT, Markham RV, Tucker WY, George RB. Postural hypoxemia in the postpneumonectomy patient. Am Rev Respir Dis 1984; 129: 1021-1022.

17 van Rossum P, Plokker HWM, Ascoop CAPL. Breathlessness and hypoxaemia in the upright position after right pneumonectomy. Eur Heart J 1988; 9: 1230-1233.

18 Smeenk FWJM, Twisk SPM, Berreklouw E, Gooszen HC, Postmus PE. Dyspnoea after pneumonectomy. Eur Respir J 1991; 4: 243-245.

19 Darremont $\mathrm{O}$, Ordronneau J, Despins $\mathrm{PH}$, et al. A rare and curable cause of acute respiratory failure after pneumonectomy: the platypnea-orthodeoxia after reopening of the foramen ovale. Rev Mal Respir 1992; 9: 557-558.

20 Buss J, Grimm V, Huck K, Jaschke W, Heene DL. Patent foramen ovale and platypnea after pneumonectomy. Dtsch Med Wochenschr 1992; 117: 1874-1880.

21 Timmermans C, Frans E, Herregods C, Decramer M, Daenen W, De Geest H. Platypnea-orthodeoxia syndrome: a report of two cases. Acta Cardiol 1993; 48: 583-590.

22 Mercho N, Stoller JK, White RD, Mehta AC. Right-to-left interatrial shunt causing platypnea after pneumonectomy. A recent experience and diagnostic value of dynamic magnetic resonance imaging. Chest 1994; 105: 931-933.

23 Landzberg MJ, Sloss LJ, Faherty CE, et al. Orthodeoxiaplatypnea due to intracardiac shunting - Relief with transcatheter double umbrella closure. Cathet Cardiovasc Diagn 1995; 36: 247-250.

24 Arnaud-Crozat E, Fortunato G, Guénot O, et al. Shunt droite-gauche auriculaire à pressions pulmonaires normales après pneumonectomie. [Right-to-left interatrial shunt with normal pulmonary pressures after pneumonectomy. Apropos of a case with severe cyanosis following left pneumonectomy]. Arch Mal Coeur Vaiss 1996; 89: 761-764.

25 Durand E, Bussy E, Gaillard JF. Lung scintigraphy in postpneumonectomy dyspnea due to a right-to-left shunt. J Nucl Med 1997; 38: 1812-1815.

26 Bakris NC, Siddiqi AJ, Fraser CD Jr, Mehta AC. Right-toleft interatrial shunt after pneumonectomy. Ann Thorac Surg 1997; 63: 198-201.

27 Vincent L, Perol M, Bourlon F, Vuillermoz S, Nesme P, Guérin JC. La fermeture percutanée du shunt droitgauche interauliculaire acquis après pneumonectomie. [Percutaneous closure of a right-left interatrial shunt acquired after pneumonectomy]. Rev Mal Respir 1998; 15: 103-105.

28 Danner I, Germaud P, Clarke JP, et al. Une dyspnée exceptionnelle en médicine interne. la platypnée-orthodéoxie après pneumonectomie. [A rare dyspnoea in internal medicine: platypnoea-orthodeoxia after pneumonectomy]. Rev Méd Interne 1988; 19: 47-50.

29 Marini C, Miniati M, Pratali L, et al. Interatrial right-to-left shunt after lung surgery: diagnostic value of perfusion lung scanning. Am J Med Sci 2004; 328: 180-184.

30 Dlabal PW, Stutts BS, Jenkins DW, Harkleroad LE, Stanford WT. Cyanosis following right pneumonectomy. Chest 1982; 81: 370-372.

31 Vacek JL, Foster J, Quinton RR, Savage PJ. Right to left shunting after lobectomy through a patent foramen ovale. Ann Thorac Surg 1985; 39: 576-578.
32 Hazard PB. Postpneumonectomy right to left interatrial shunt: obliteration with balloon-tip vascular catheter. Crit Care Med 1987; 15: 618-619.

33 Berry L, Braude S, Hogan J. Refractory hypoxaemia after pneumonectomy: diagnosis by transoesophageal echocardiography. Thorax 1992; 47: 60-61.

34 Saada J, Almosni M, Dahan M, Bellamy J. Hypoxémie réfractaire par ouverture transitoire $\mathrm{du}$ foramen ovale après pneumonectomie. [Refractory hypoxaemia caused by transient opening of the foramen ovale after pneumonectomy]. Rev Pneumol Clin 1994; 50: 168-171.

35 Godart F, Porte HL, Rey C, Lablanche JM, Wurtz A. Postpneumonectomy interatrial right-to-left shunt: successful percutaneous treatment. Ann Thorac Surg 1997; 64: 834-836.

36 Alfaifi S, Lapinsky SE. Trepopnea due to interatrial shunt following lung resection. Chest 1998; 113: 726-727.

37 Godart F, Rey C, Prat A, et al. Atrial right-to-left shunting causing severe hypoxemia despite normal right-sided pressures. Report of 11 consecutive cases corrected by percutaneous closure. Eur Heart J 2000; 21: 483-489.

38 Mall JW, Vogel B, Grohmann A, Müller JM. Re-opened foramen ovale-a rare cause of postoperative dyspnea following pneumonectomy. Thorac Cardiov Surg 2000; 48: 308-310.

39 Krowka MJ, Cortese DA. Hepatopulmonary syndrome current concepts in diagnostic and therapeutic considerations. Chest 1994; 105: 1528-1537.

40 Dogan SA, Rezai K, Kichner PT, Stuhlmuller JE. A scintigraphic sign for detection of right-to-left shunts. J Nucl Med 1993; 34: 1607-1611.

41 Christiansen KH, Morgan SW, Karich AF, Takaro T. Pleural space following pneumonectomy. Ann Thorac Surg 1965; 1: 298-304.

42 Silver AV, Espinas B, Byron FX. The fate of the postresection space. Ann Thorac Surg 1966; 2: 311-336.

43 De Castro S, Cartoni D, Fiorelli M, et al. Morphological and functional characteristics of patent foramen ovale and their embolic implications. Stroke 2000; 31: 2407-2413.

44 Eggebrecht $H$, Naber CK, Plato C, Erbel R, Bartel T. Analysis of fossa ovalis membrane velocities by transesophageal Doppler tissue echocardiography: a novel approach to functional assessment of patent foramen ovale. J Am Soc Echocardiogr 2004; 17: 1161-1166.

45 Strunk BL, Cheitlin MD, Stulbarg MS, Schiller NB. Rightto-left interatrial shunting through a patent foramen ovale despite normal intrathoracic pressures. Am J Cardiol 1987; 60: 413-415.

46 Baumgartner F, Omari B, Lee J, et al. Survival after trauma pneumonectomy: the pathophysiologic balance of shock resuscitation with right heart failure. Am Surg 1996; 62: 967-972.

47 Patel RL, Towsend ER, Fountain WS. Elective pneumonectomy: factors associated with morbidity and operative mortality. Ann Thorac Surg 1992; 54: 84-88.

48 Adolph EA, Lacy WO, Hermony YI, Wexler LF, Javaheri S. Reversible orthodeoxia and platypnea due to right-to-left shunting related to pericardial effusion. Ann Int Med 1992; 116: 138-139.

49 Guérin P, Lambert V, Godart F, et al. Transcatheter closure of patent foramen ovale in patients with platypneaorthodeoxia: results of a multicentric French registry. Cardiovasc Intervent Radiol 2005; 28: 164-168. 